\title{
Numerical simulation of PV/T air collector with gradually expanding and shrinking channels
}

\author{
Zhangyang Kang ${ }^{1}$, Zhaoyang $\mathrm{Lu}^{1}$, Manfeng $\mathrm{Li}^{1}{ }^{1}{ }^{*}$ and Qiongqiong $\mathrm{Yao}^{2}$ \\ ${ }^{1}$ School of Environmental and Municipal Engineering, North China University of Water Resources and Electric Power, Zhengzhou \\ 450046, PR China \\ ${ }^{2}$ Metrology Center of Electric Power Research Institute, State Grid Henan Electric Power Company, Zhengzhou 450051, Henan, China
}

\begin{abstract}
CFD technology isused to simulate the PV/T air collector with gradually expanding and shrinking channels, and thegradually expanding and shrinking channels have influence on the temperature of the heat absorbing plate and the temperature outlet air of the PV/T air collector is analyzed. The result shows that the expanding and shrinking channels have adverse effects on the massairflow in the collector, causing the temperature of the heat absorption plate to rise. Increasing the $\mathrm{m}$ can effectively reduce the temperature of the heat absorption plate and enhance the photoelectricefficiency of the system, and the temperature of air outlet will be enhanced. However, the mass flow has greater influence on the outlet temperature, and the increase of the mass flow makes the outlet temperature decrease more obvious. As the air mass flow increases, the temperature difference between $\mathrm{m}=0.0081$ and $\mathrm{m}=0.0169$ will increase. When the massflow is $0.0029 \mathrm{~kg} / \mathrm{s}$, the temperature difference is $1.69^{\circ} \mathrm{C}$; when the massflow is 0.0169 , the temperature difference is $2.35^{\circ} \mathrm{C}$.
\end{abstract}

\section{Introduction}

The depletion of conventional fossil fuels and the over production of greenhouse gases in human activities have led to the search for other forms of energy all over the world, and the research and application of solar energy has also been widely concerned. Compared with other forms of energy, the biggest advantage of solar energy is renewable, rich, eco-friendly, without any ecological pollution. Solar energy can be converted into both electrical and thermal energy by PV/T system, which can effectively improve the utilization efficiency of solar energy. Air and water are the cooling medium of most $\mathrm{PV} / \mathrm{T}$ systems, but due to physical properties and other reasons, the efficiency of air-cooled PV/T system is not as high as that of water-cooled PV/T system. Air-cooled $\mathrm{PV} / \mathrm{T}$ system is the main research object in the early stage due to construction cost and operation cost.

In the past decades, scholars in many countries have done a lot of experiments and simulation studies on PV/T system. Hegazy et al. [1] compared and studied the thermal, electrical and comprehensive performance of four different designs of solar air collectors, and established a mathematical model for each type of collector. The effects of specific mass air flow, the selectivity of absorption plate and photovoltaic cell on the performance of the cell were investigated by numerical simulation. Kong et al.[2] established the performance mathematical model of the steady-state plate solar collector, they simulated the thermal performance of the plate solar collector through the programmed thermal performance simulation program, and analyzed in detail the influence characteristics of environmental parameters, operational parameters and structural parameters on the instantaneous efficiency of the collector. Alvarez et al. [3] designed a new type of flat plate solar collector with corrugated channel, established a mathematical model for the collector based on the finite element analysis method, and carried out numerical simulation and experimental verification. Hamdy et al. [4] studied solar air collectors with different absorption plate structures and different mass air flow modes, and analyzed the influence of different absorption plate structures and different air massflow modes on the performance of the collector through experiments. Tonui et al.[5] studied the natural ventilation PV/T system with experimental and simulation methods, and analyzed the influence of air passage depth, collector inclination angle, collector length and outlet area on the performance of PV/T air model. Guochao, jijie et al. [6-8] proposed a multi-functional solar photovoltaic $/ \mathrm{T}$ collector, which can choose two working modes: hot water and hot wind. And its photoelectric photothermal performance was tested and simulated. The result shows that the method can realize the efficient utilization of solar energy.

Blowing air into the passage and pumping air out from the passage are two methods to study PV/T air system under forced ventilation. Both methods have advantages and disadvantages and are suitable for different situations. These two methods have their own advantages and disadvantages and are suitable for different situations. In this paper, the way of pumping air

\footnotetext{
*Corresponding author: limanfeng@ncwu.edu.cn
} 
from the passage is selected to maintain the negative pressure in the passage. The temperature distribution in solar PV/T collector with gradually expanding and shrinking channels is simulated by numerical method. And the accuracy of the model is verified by numerical simulation and experimental data comparison. Finally, the influence parameters are analyzed based on the structure.

\section{Model construction and validation}

\subsection{Geometric and physical models}

The numerical simulation in this paper is carried out in a three-dimensional model with gradually expanding and shrinking channels. The structure of the collector is shown in Fig.1, including glass cover plate, solar cell, heat absorption plate, air inlet and outlet, gradually expanding and shrinking tube, and insulation layer. The endothermic board material is aluminum, $1964 \mathrm{~mm}$ long, $964 \mathrm{~mm}$ wide, $3 \mathrm{~mm}$ thick, the glass cover is single-layer glass, length and width and endothermic board, $3 \mathrm{~mm}$ thick, The solar cell is laminated on the heat absorption plate, and the air gap between the heat absorption plate and the glass cover is $20 \mathrm{~mm}$ apart, and the air circulation between the heat insulation layer on the back is $30 \mathrm{~mm}$ apart. Insulation material is glass fiber, thickness of 30 $\mathrm{mm}$.

\subsection{Numerical model}

Hexahedral mesh model is used in numerical calculation. And velocity inlet and pressure outlet boundary conditions are adopted. Andnoslip boundary condition is used on inner wall surface. The sun shines directly on the glass plate and shinesthrough the glass plate on the heat absorption plate. TheMix boundary condition is set for the glass cover plate. The convective and radiative heat transfer between the glass cover and the outside is considered. The transmittance, emissivity and absorptivity of the glass are set to $0.9,0.9$ and 0.1 respectively.

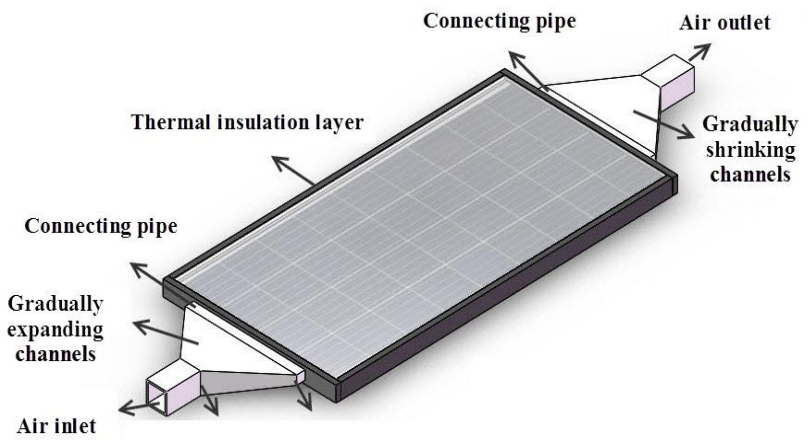

Fig.1.The schametic ofPV/T collector.

The upper part of the heat absorbing plate is in contact with the air layer, and the lower part is in contact with the mass air flow layer, so the heat transfer is complex, which involves the heat transfer between the solid and the gas. There is a phenomenon of fluid solid coupled heat transfer. It is assumed to be a wall surface with thickness because of its thickness and coupled boundary conditions are selected for heat transfer calculation. The heat absorption plate is made of aluminum. The monomer silicon cell is laminated on the heat absorption plate, and the uncovered part of the cell is a black absorption coating. Assume that the heat sink has the same physical properties as the battery because it is only $3 \mathrm{~mm}$ thick. Solar radiation absorption rate is 0.9 and reflectivity is 0.1 . Convention conditions were set on the outer surface of other structures to consider convection heat transfer. The governing equation is discretized by finite volume method. The second-order upwind format and appropriate sub-relaxation factor are selected for the discretization of the governing equation. And use the SIMPLE algorithm to handle the coupling of pressure and speed. In the process of simulation, Boussinesq hypothesis is adopted for air interlayer air, which can reduce the calculation amount under the condition of small temperature difference and natural convection, thus accelerating the convergence speed.

\section{Simulation result and analysis}

\subsection{Validation of grid and model}

The grid independence of the model is verified, and the model was tilted $35^{\circ}$ to the south. The ambient temperature of the model was set as $T_{a}=283 \mathrm{~K}$, the working flow of the model was set as $Q=0.039 \mathrm{~kg} / \mathrm{s}$, and the solar radiation intensity was set as $G=787 \mathrm{w} / \mathrm{m}^{2}$.It is necessary to consider the comprehensive influence of the number of grids on the temperature of the heat absorption plate and the outlet temperature of the system, so the comprehensive efficiency calculation formula of reference [7] system is used to judge the influence of grid number on the model through the comprehensive efficiency. The trend of $\mathrm{PV} / \mathrm{T}$ system comprehensive efficiency under different number of grid nodes is shown in Fig.2. When the number of grid is 2.029 million, the increase of grid has little effect on the calculation result. The integrated efficiency deviation of PV/T system with 2.029 million grids and 3.139 million grids was $0.3 \%$. Therefore, when the number of meshes is 2.029 million, the accuracy requirement can be satisfied and the meshing independence solution can be obtained.

In the calculation process, the intake temperature Tin was changed to $283,293,303$ and $313 \mathrm{~K}$ to verify the validity of the model. The simulated values of the outlet temperature and the temperature of the heat absorption plate were compared with the experimental values in reference [7], and the results were shown inFig.3. 


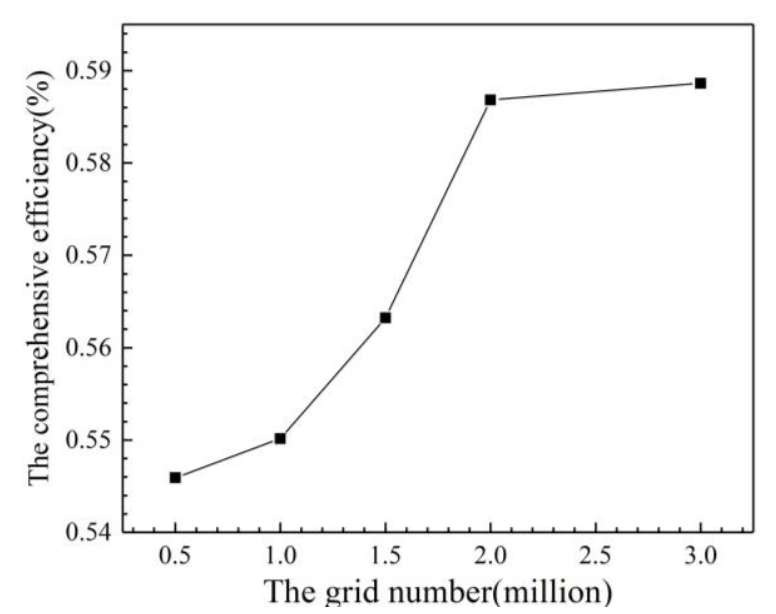

Fig.2. The trend of PV/T collector comprehensive efficiency with the number of grid nodes.

The average deviation between the simulated values of outlet temperature and the heat absorption plate temperature and the experimental values in the reference is $3.8 \%$ and $1.7 \%$, respectively, indicating that the current simulated values are in good agreement with the experimental results in the reference. The simulation result shows that the connection between the variable diameter channel and the air passage can effectively reduce the eddy current. Therefore, the model is improved by ignoring the connection section, establishing a new model, and retaining the original boundary conditions for simulation. In addition, the Angle of the gradually expanding and shrinking pipe is changed by changing the area of the air inlet and outlet to simulate and analyze the system.

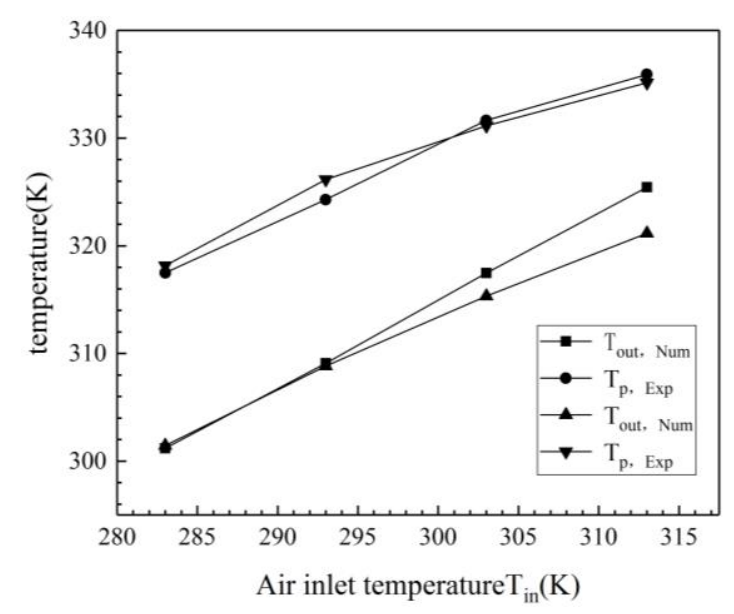

Fig.3.Comparisons between simulated andexperimental values of outletand endothermic plate temperatures.

\subsection{Analysis of simulation result}

Seting the area of air inlet and outlet is $\mathrm{m}$, see Table 1 forvalues.

Table 1. The area of air inlet and outletm $\left(\mathrm{m}^{2}\right)$

\begin{tabular}{ll}
\hline $\begin{array}{l}\text { The size of air inlet } \\
\text { and outlet }(\mathrm{cm})\end{array}$ & $\begin{array}{l}\text { The area of air inlet } \\
\text { and outlet } \mathrm{m}\left(\mathrm{m}^{2}\right)\end{array}$ \\
\hline $9 \times 9$ & 0.0081 \\
$10 \times 10$ & 0.01 \\
$11 \times 11$ & 0.0121 \\
$12 \times 12$ & 0.0144 \\
$13 \times 13$ & 0.0169 \\
\hline
\end{tabular}

When the massair flow $Q=0.039 \mathrm{~kg} / \mathrm{s}$, the temperature distribution of the heat absorption plate of PV/T system is shown in Fig.4.Table $1 \mathrm{~m}$ shows the area of air inlet and outlet. It can be found from the distribution that when the $\mathrm{m}$ increases, the temperature distribution of the heat absorption plate tends to be uniform, It means that the air flow in the air passage is gradually uniform, and the air can take away the heat transferred from the heat absorption plate better. Fig. 6shows the variation trend of average temperature of heat absorbent plate in $\mathrm{PV} / \mathrm{T}$ system with inlet and outlet pipe diameter. From the overall trend, the average temperature decreases with the increase of $\mathrm{m}$. 


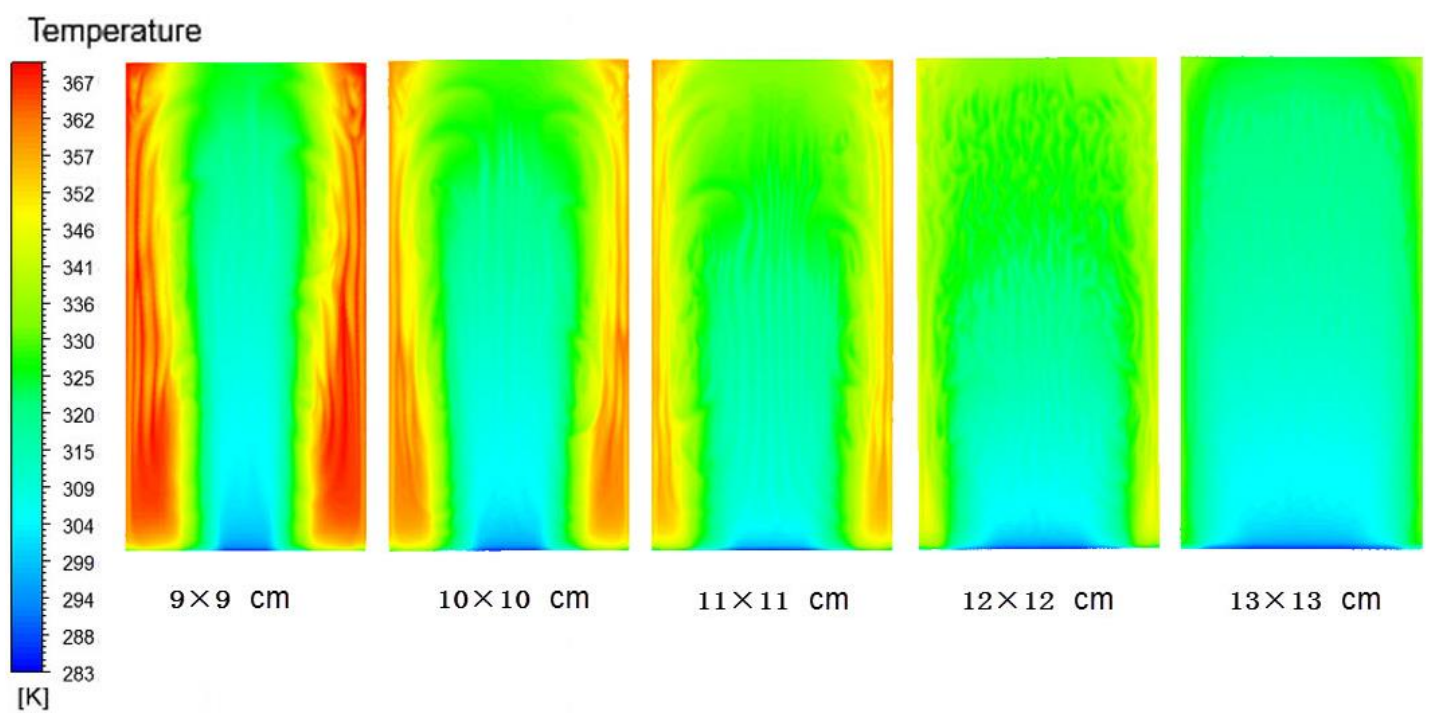

Fig.4.Heat absorption plate temperature distribution.

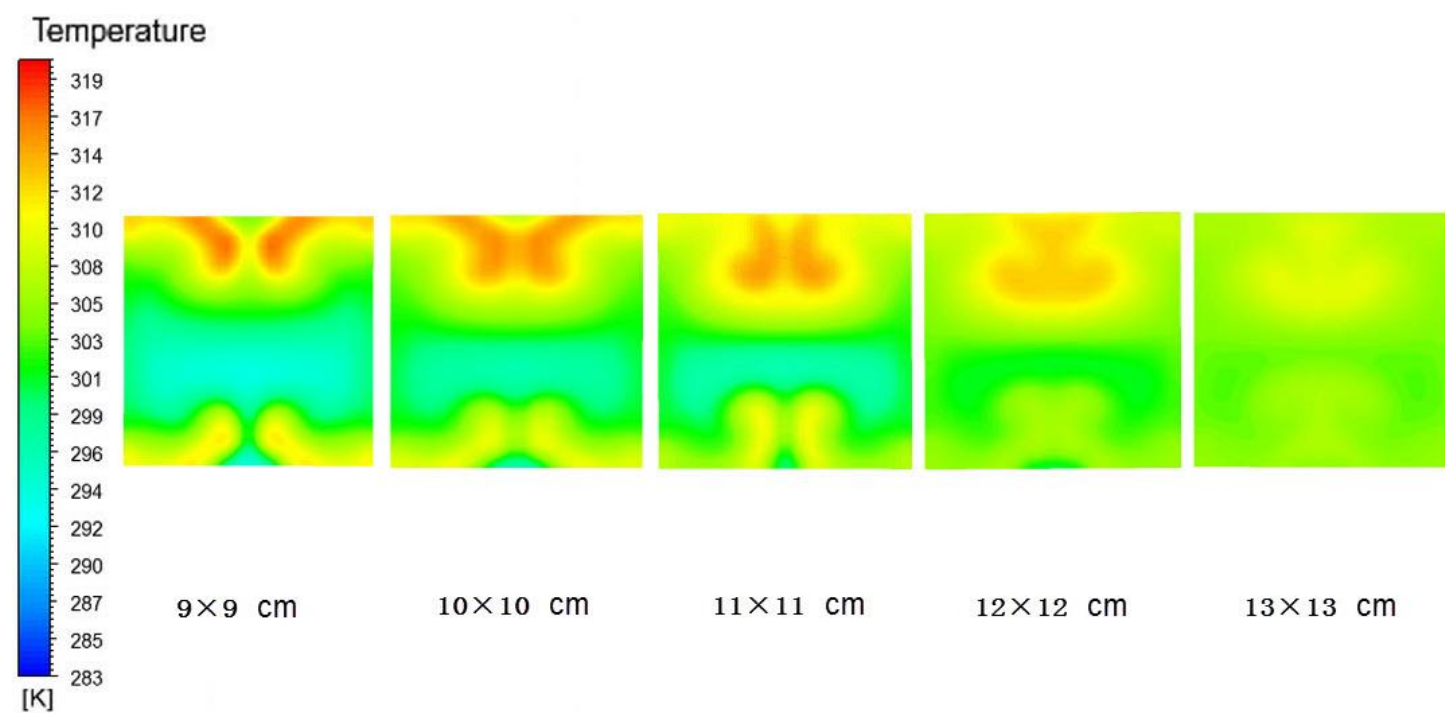

Fig.5. Air outlet temperature distribution

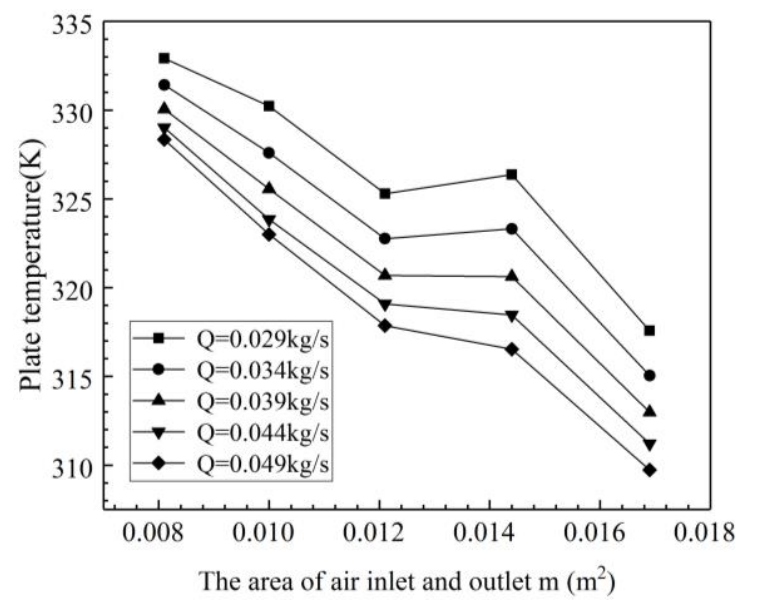

Fig.6. The temperature of the heat absorption plate varies with the $\mathrm{m}$.

When massair flow rate $Q=0.039 \mathrm{~kg} / \mathrm{s}$, the temperature distribution of the air outlet of $\mathrm{PV} / \mathrm{T}$ system is shown in Fig. 5, and the change trend of average temperature of the air outlet of $\mathrm{PV} / \mathrm{T}$ system with $\mathrm{m}$ is shown in Fig. 7.It is found from the temperature distribution that the temperature at the air outlet is gradually distributed evenly and the distribution area of the low temperature is gradually narrowed. Combined with the temperature distribution of the endothermic plate, it shows that increasing the $\mathrm{m}$ of the system can effectively improve the air distribution in the flow channel, and reduce the size of the retardation area in the flow channel, and can better remove the heat in the flow channel. From the result of Fig 7, it can be concluded that increasing the $\mathrm{m}$ will enhance the average air outlet temperature. However, the Mass massair flow has greater influence on the outlet temperature, and the increase of the flow makes the outlet temperature drop more obvious. As the mass air flow rate increases, the temperature difference between $\mathrm{m}=0.0081$ and $\mathrm{m}=0.0169$ will increase. When the flow is $0.0029 \mathrm{~kg} / \mathrm{s}$, the temperature difference is $1.69^{\circ} \mathrm{C}$; when the flow is 0.0169 , the temperature difference is $2.35^{\circ} \mathrm{C}$. The performance of $\mathrm{PV} / \mathrm{T}$ system will be adversely affected by the expanding and shrinking structure. Therefore, in practical projects, the use of some equipment with rectifying function at the air inlet will 
enhance the performance of $\mathrm{PV} / \mathrm{T}$.

\section{Conclusions}

According to the simulation result, the following conclusions can be drawn:

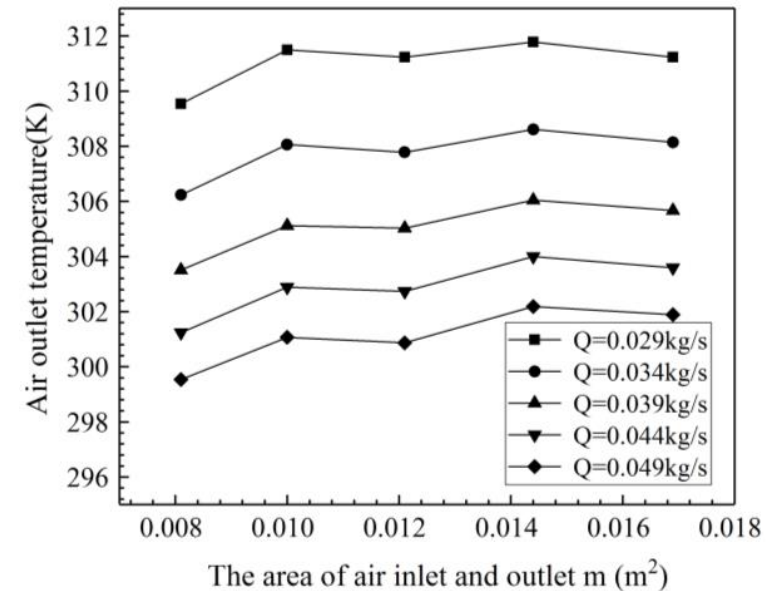

Fig.7.The temperature of air outlet varies with $\mathrm{m}$

1.Changing the area of air inlet and air outlet can effectively improve the distribution of air in the flow channel, avoid the heat accumulation of air in the flow channel, effectively reduce the temperature of the heat absorption plate, and enhance the photoelectric efficiency of the system.

2.Increasing the area of the air inlet and outlet, the temperature of air outlet will be enhanced, and the photothermal efficiency of the system will be improved. However, the massair flow has greater influence on the outlet temperature, and the increase of the massair flow makes the outlet temperature drop more obvious. As the air mass air flow rate increases, the temperature difference between $\mathrm{m}=0.0081$ and $\mathrm{m}=0.0169$ will increase.

\section{References}

1. A. A. Hegazy, Energ Convers. Manage. 41, 861-881(2000).

2. X. Kong, L. Lin, Y. Li, D. Ma. ActaEnergiae Solaris Sinica.34, 1404-1409(2013).

3. A. Alvarez, O. Cabeza, M. C.Muñiz, et al. Energy, 35, 3707-3716(2010).

4. H. Hassan, S. Abo-Elfadl. Renew Energy.116, 728-740(2018).

5. J. K. Tonui, Y. Tripanagnostopoulos. Sol Energy. 82, 1-12(2008).

6. C. Guo, J.Ji, W. Sun, et al. ActaEnergiae Solaris Sinica.38, 372-377(2017).

7. C. Guo, J.Ji, W. Sun, et al. Energy.87, 470-480(2015).

8. J Ji, C Guo, W Sun, et al. Energ Convers. Manage. 88, 650-656(2014). 